\title{
Synergism of rMV-Hu191 with cisplatin to treat gastric cancer by acid sphingomyelinase-mediated apoptosis requiring integrity of lipid raft microdomains
}

\author{
Yao Lv ${ }^{1}$. Chu-di Zhang ${ }^{2} \cdot$ Yi-long Wang ${ }^{2}$ - Dong-ming Zhou ${ }^{2} \cdot$ Meng-ying Zhu $^{2} \cdot$ Xiao-qiang Hao $^{2}$. Jin-hu Wang ${ }^{2}$. \\ Wei-zhong $\mathrm{Gu}^{2} \cdot$ Hong-qiang Shen ${ }^{2} \cdot$ Jin-gan Lou ${ }^{2} \cdot$ Ben-qing Wu ${ }^{3} \cdot$ Pei-chun $\mathrm{Chen}^{3} \cdot$ Zheng-yan Zhao $^{2}$
}

Received: 14 March 2021 / Accepted: 29 June 2021 / Published online: 12 July 2021

(c) The Author(s) 2021

\begin{abstract}
Background DDP-based chemotherapy is one of the first-line treatment in GC. However, the therapeutic efficacy of DDP is limited due to side effects. Therefore, it is of great significance to develop novel adjuvants to synergize with DDP. We had demonstrated previously that rMV-Hu191 had antitumor activity in GC. Here we examined the synergism of rMV-Hu191 with DDP in vitro and in vivo.

Methods Cellular proliferation, the synergistic effect and cell apoptosis were evaluated by CCK- 8 assay, ZIP analysis and flow cytometry, respectively. The protein levels and location of ASMase were monitored by western blot and immunofluorescence assay. shRNA and imipramine were used to regulate the expression and activity of ASMase. M $\beta C D$ was administrated to disrupt lipid rafts. Mice bearing GC xenografts were used to confirm the synergism in vivo.

Results From our data, combinational therapy demonstrated synergistic cytotoxicity both in resistant GC cell lines from a Chinese patient and drug-nonresistant GC cell lines, and increased cell apoptosis, instead of viral replication. Integrity of lipid rafts and ASMase were required for rMV-Hu191- and combination-induced apoptosis. The ASMase was delivered to the lipid raft microdomains at the initial stage of rMV-Hu191 treatment. In vivo GC mice xenografts confirmed the synergism of combinational treatment, together with increased apoptosis and trivial side-effects.

Conclusions This is the first study to demonstrate that rMV-Hu191 combined with DDP could be used as a potential therapeutic strategy in GC treatment and the ASMase and the integrity of lipid rafts are required for the synergistic effects.
\end{abstract}

Keywords Gastric cancer · Recombinant Chinese Hu191 measles virus · Cisplatin · ASMase · Lipid rafts

\begin{tabular}{llll}
\multicolumn{2}{l}{ Abbreviations } & ATCC & American Type Culture Collection \\
GC & Gastric cancer & DMEM & Dulbecco's modified Eagle's medium \\
DDP & Cisplatin & Z-VAD & Z-VAD-FMK \\
rMV-Hu191 & Recombinant Hu191 strain of measles virus & MOI & Multiplicity of infection \\
MV & Measles virus & IC50 & Half maximal inhibitory concentration \\
ASMase & Acid sphingomyelinase & TCID 50 & The median tissue culture infective dose \\
SM & Sphingomyelin & DMSO & Dimethyl sulfoxide \\
M $\beta C D$ & Methyl- $\beta$-cyclodextrin & PFA & Paraformaldehyde \\
CTB & Cholera toxin subunit B & MV-P & Anti-measles phosphoprotein \\
CCK-8 & Cell counting kit-8 & Alb & Albumin \\
ZIP & Zero interaction potency & Glb & Globulin \\
FBS & Fetal bovine serum & AST & Aspartate aminotransferase \\
& & ALT & Alanine aminotransferase \\
\hline Yao Lv and Chu-di Zhang contributed equally to this work. & BUN & Blood urea nitrogen \\
\hline \multirow{2}{*}{ Zheng-yan Zhao } & Cr & Creatine \\
\multicolumn{2}{rl}{ zhaozy@ zju.edu.cn } & IF & Immunofluorescence \\
Extended author information available on the last page of the article & H\&E & Immunohistochemistry \\
\end{tabular}




\section{Introduction}

Gastric cancer (GC) is the fifth most common malignancy worldwide, and its overall mortality rate is the third highest in all types of cancers $[1,2]$. Currently, the main therapeutic methods used to treat GC include surgery, radiotherapy, chemotherapy and neoadjuvant therapy [3]. First-line treatment of advanced gastric cancer is based on cisplatin (DDP) and 5-fluorouracil [4]. However, the therapeutic efficacy of DDP treatment to GC patients is limited due to the toxicity induced by the relatively high dose applied in conventional chemotherapy, as well as the frequent development of drug resistance [5, 6]. Therefore, novel adjuvants are always desired with hope to increase the potency of the drugs, to reduce the side effects, and to counteract chemoresistance.

Combining therapeutic modalities have an ability to produce additive or synergistic effect exceeding either approach alone. Combination of oncolytic virotherapy, chemotherapy, or immunotherapy has been investigated in recent pre-clinical and clinical studies to maximize the efficacy [7-10]. Measles virus (MV), one of the oncolytic viruses, has been investigated as a new treatment modality against a number of tumor entities including hepatocellular carcinoma, breast cancer, pancreatic cancer, and colon cancer [11-14]. Several oncolytic MV strains had been undergone clinical trials as antitumor agents $[15,16]$. Phase I/II clinical trials had shown promise but treatment efficacy needs to be enhanced, otherwise might endanger its broad clinical success [17]. Furthermore, previous studies showed that combinational treatment with oncolytic measles vaccine viruses enhanced killing of therapy-induced senescent tumor cells including hepatoma, pancreatic cancer, and mammary gland carcinoma with chemotherapeutics including gemcitabine, doxorubicin, and paclitaxel [18]. Oncolytic MV in combination with chemotherapeutics shows promising prospects, since such regimens could efficiently eliminate both primary tumors and metastases.

The safety of the measles vaccine has been proved worldwide in controlling measles [19], and the live-attenuated Chinese Hu191 measles virus strain has the same safety record for 50 years [20]. Recently in our laboratory, rMV-Hu191, a recombinant Hu191 strain of measles virus has been successfully established [21]. It has been found in previous studies that rMV-Hu191 alone could be used as a potentially effective therapeutic agent in gastric cancer and colorectal cancer treatment $[22,23]$. Whether the rMVHu191 could synergize with DDP in GC is not reported to the date. This study evaluated the antitumor activity of rMV-Hu191 combined with DDP against two drugs nonresistant human GC cell lines and one multi-drug-resistant signet ring cell line from a Chinese male signet ring cell gastric cancer patient and mice bearing xenografts. Furthermore, the underlying mechanisms of the combinational therapy were discussed.

Apoptosis, one type of cell death models, is mainly regulated by intrinsic, extrinsic apoptotic pathways and proapoptotic lipid signaling pathways [24, 25]. We have previously shown that rMV-Hu191 alone could induce apoptotic cell death requiring integrity of lipid raft microdomains in human gastric cancer [22]. The present study further explores the role of lipid rafts in rMV-Hu191-induced apoptosis. Lipid rafts as major platforms for signal regulation in cancer are high content of cholesterol and sphingomyelin (SM) membrane microdomains [26]. Acid sphingomyelinase (ASMase) is a lysosomal phosphodiesterase that catalyzes the hydrolysis of SM to produce phosphocholine and ceramide. Ceramide is a pro-apoptotic protein regulating a key initiative step in apoptosis [27]. The binding of microbial pathogens and membrane damage could lead to the activation of ASMase and translocation of ASMase from lysosome to the lipid raft microdomains, and the subsequent generation of ceramide promotes the initiation of the apoptosis [28]. Thus, we hypothesized that ASMase and lipid rafts were required for rMV-Hu191 inducing apoptotic cell death in GC cells.

Despite that DDP binds to nucleic acids, thiol-containing peptides, microfilaments, and membrane phospholipids, DNA is generally considered as the major biological target of DDP [29]. The main mechanism of DDP is through crosslinking DNA and the subsequent prevention of DNA replication and transcription, which ultimately leads to cell death through interconnections between apoptosis and necrosis pathways [30]. In literature reports, DDP could induce caspase-dependent apoptosis in GC [31, 32]. Therefore, we hypothesized that rMV-Hu191 could synergize with DDP to induce tumor cell apoptotic death.

The novel chemovirotherapy strategy being investigated here could be of clinical benefit by effectively reducing tumor burden and decreasing chemo-resistance together with toxicity. Furthermore, we uncovered a novel mechanism of virus-induced sensitization to DDP therapy.

\section{Materials and methods}

\section{Cell culture and reagents}

The BGC-823 and SGC-7901 cells were purchased from the Cell Bank of the Chinese Academy of Sciences, Shanghai, China, and the multi-drug-resistant signet ring cell GCSR1 [33] was a general gift of professor Li-song Teng. Cell morphology of GCSR 1 in culture maintained in vitro for over 90 passages, is similar to the cells from 
the patient. The BGC-823 and GCSR1 cells were cultured in RPMI 1640 medium (Life Technologies, USA) supplemented with $10 \%$ FBS, and the SGC-7901 cells were supplemented with $20 \%$ FBS. African green monkey kidney Vero cells were purchased from the American Type Culture Collection (ATCC, USA), and cultured in DMEM (Life Technologies, USA) supplemented with 10\% FBS. All cells were cultured at $37^{\circ} \mathrm{C}$ with $5 \% \mathrm{CO}_{2}$ and saturated moisture. Reagents: cisplatin (Sigma, P4394), Z-VADFMK (ApexBio, A1902), Methyl- $\beta$-cyclodextrin (Sigma, 332615), imipramine (ApexBio, C4117).

\section{Cell viability assays}

BGC-823, SGC-7901 and GCSR 1 cells were plated at $4 \times 10^{3}$ or $3 \times 10^{3}$ cells per well in 96 -well plates. After $24 \mathrm{~h}$, cells were treated with rMV-Hu191 at different multiplicity of infection (MOI), and cisplatin (DDP) was then added $24 \mathrm{~h}$ post infection. Cell viability was calculated based on standard curves by CCK8 assay (Dojindo Molecular Technologies, USA) at every 24-h interval.

\section{Zero interaction potency (ZIP) analysis}

We determined the complete combination matrix for antagonism or synergy using the ZIP model. This new method is based on the hypothesis that two non-interacting drugs will simply affect their dose-response curves, but not the half maximal inhibitory concentration (IC50) or the shape of the curve. Therefore, any deviation in these values detected when combining with another drug can indicate antagonism or synergism [34, 35]. Data from individual dose response experiments were used to calculate the ZIP scores. For this analysis we used the R package "SynergyFinder 1.0." (www.synergyfinder.fimm.fi).

\section{Virus construction, titration and replication assays}

rMV-Hu191 was constructed as previously described [21]. Virus titers were calculated on Vero cells by the TCID 50 method [36]. For virus replication assays, cells were plated at $2 \times 10^{5}$ per cell in six-well plates. After $24 \mathrm{~h}$, cells were infected with $\mathrm{rMV}-\mathrm{Hu} 191$ at $\mathrm{MOI}=0.1$ or $\mathrm{MOI}=1$ in Opti-MEM medium (Life Technologies, USA) for $2 \mathrm{~h}$. Then the virus containing medium was replaced with fresh media. DDP was added at indicated dose $24 \mathrm{~h}$ post infection. Cells were harvested with supernatant at indicated time intervals. Then virus titers were measured by TCID 50 assay on Vero cells after two freeze-thaw cycles and centrifugation.

\section{Disruption and isolation of cholesterol-rich 'lipid rafts'}

Methyl- $\beta$-cyclodextrin $(\mathrm{M} \beta \mathrm{CD})$ was known as a compound to extract cholesterol from biomembranes. Drug stocks $(50 \mathrm{mg} / \mathrm{ml})$ were prepared in PBS and stored at $4{ }^{\circ} \mathrm{C}$ until use. To disrupt lipid rafts, cells were incubated with $7.5 \mathrm{mM}$ $\mathrm{M} \beta C D 2 \mathrm{~h}$ prior to rMV-Hu191 infection and then $2 \mathrm{mM}$ $\mathrm{M} \beta C D$ for $48 \mathrm{~h}$ after combinational treatment.

The lipid raft fractions were separated as previously described [22]. Briefly, GC cells after desired treatments were incubated with ice-cold solubilization buffer. After incubation, the sample was homogenized with needle and centrifuged at $500 \mathrm{~g}$ for $5 \mathrm{~min}$ at $4{ }^{\circ} \mathrm{C}$ (Allegra 6R, Beckman Coulter, USA). The supernatant was mixed with TritonX-100 (Solarbio, China) at the final concentration of $0.5 \%$ (w/v, in solubilization buffer). The membrane fractions mixed with sucrose were centrifuged at $200,000 \mathrm{~g}$ at $4{ }^{\circ} \mathrm{C}$ for $14 \mathrm{~h}$ (Optima ultracentrifuge, Beckman Coulter, USA). Then ten serial aliquots were collected from the top and labelled as $1-10$. Finally, all fractions were detected by Western blotting as described below.

\section{Functional inhibition of ASMase}

Imipramine as a specific ASMase inhibitor could block the function of ASMase. A $300 \mathrm{mM}$ stock of imipramine was prepared in DMSO and stored at $-20^{\circ} \mathrm{C}$. For ASMase functional inhibition assays, imipramine was incubated at $25 \mu \mathrm{M}$ in BGC-823 cells and $50 \mu \mathrm{M}$ in SGC-7901 cells for $72 \mathrm{~h}$ after rMV-Hu191 infection.

\section{Construction of ASMase-knockdown SGC-7901 cell clones}

We used shRNA targeting the ASMase gene (SMPD1) to reduce ASMase expression and shCtrl as a negative control. shASMase and shCtrl plasmids obtained from Genechem (Shanghai, China) were packaged as lentiviral constructs using lipofectamine 2000 (Invitrogen, 11668027) and then transfected to the SGC-7901 cells. Stable transfectants were screened with puromycin $(1: 12,000)$ to obtain single cell clone for amplification. Protein levels of ASMase were measured by Western blotting.

\section{Flow cytometry analysis}

A density of $1 \times 10^{6} \mathrm{GC}$ cells at indicated treatments were harvested, washed twice in PBS and stained with Annexin V FITC Apoptosis Detection Kit (BD Biosciences, 556547) following the manufacturer's instructions. Triplicates for 
each group were detected by a flow cytometer (Navios, Beckman Coulter, USA) and analyzed with Flowjo 10.0 software (Tree Star Inc, USA).

\section{Western blotting}

Cells after desired treatment were harvested at indicated times, washed once with PBS, and then were lysed in RIPA buffer (Beyotime, P0013B) with phosphatase and protease inhibitors. $30 \mu \mathrm{g}$ of proteins per well were separated by SDSPAGE gel and electroblotted onto Immuno-blot PVDF membrane (Bio-Rad Laboratories, 1620177). The membranes blocking with $5 \%$ nonfat milk at room temperature for $1 \mathrm{~h}$, were probed with primary antibodies at $4{ }^{\circ} \mathrm{C}$ overnight, followed by secondary antibodies at room temperature for $1 \mathrm{~h}$. Then the membranes were visualized using an EZ-ECL detection kit (Biological Industries, 20-500-120). For Western blot analysis: anti- $\beta$-actin (CST, 4970S), anti-caspase-3 (CST, 9665S), anti-PARP (CST, 9542S), anti-Acid sphingomyelinase (ASMase, abcam, ab74281), anti-flotillin 1 (abcam, ab133497), secondary HRP-linked anti-rabbit IgG (CST, 7074S), secondary HRP-linked anti-mouse IgG (CST, 7076S).

\section{Immunofluorescence}

BGC-823 and SGC-7901 cell lines were cultured in 24-well plates at $4 \times 10^{5}$ cells per well. The cells after indicated treatment were gently washed with PBS, fixed in $4 \%$ paraformaldehyde (PFA) for $30 \mathrm{~min}$, permeabilized by $0.1 \%$ TritonX-100, and blocked by $2 \%$ BSA. Cells were incubated with mouse anti-measles phosphoprotein (MV-P, abcam, ab43820), followed by Alexa Fluor ${ }^{\circledR} 594$ donkey anti-mouse $\mathrm{IgG}(\mathrm{H}+\mathrm{L})$ (Invitrogen, A-21203) and DAPI (Beyotime, C1005) in the dark, images were captured using Zeiss cLSM780 microscope. For co-localization analysis, cells were stained with Alexa 488-conjugated CTB (Invitrogen, C-34775) for $2 \mathrm{~h}$ at $37{ }^{\circ} \mathrm{C}$ incubator before fixation by $4 \%$ PFA. Then cells were incubated with anti-Acid sphingomyelinase (ASMase, abcam, ab83354) at $4{ }^{\circ} \mathrm{C}$ overnight, followed by Alexa Fluor ${ }^{\circledR} 594$ goat anti-rabbit IgG $(\mathrm{H}+\mathrm{L})$ (Invitrogen, A-11012) and DAPI in the dark. Images were captured using Lecia TCS SP8 confocal laser scanning microscope.

\section{In vivo antitumor studies}

All institutional and national guidelines for the care and use of laboratory animals were followed. The animal experiments were handled according to the animal ethical committee of Zhejiang Chinese Medical University. $1 \times 10^{6}$ BGC-823 cells suspended in $100 \mu \mathrm{l}$ PBS were subcutaneously injected into the right flank of athymic nude mice (3-5 weeks, male) obtained and housed in the animal center of Zhejiang Chinese Medical University.

On day 5 post implantation, mice were randomly divided into four groups $(n=10)$ when tumor volume reached approximately $30-50 \mathrm{~mm}^{3}\left(V=\right.$ length $\times$ width $\left.^{2} / 2\right)$.

From this day, mice were injected intratumorally with $1.4 \times 10^{7}$ (TCID 50) of rMV-Hu191 suspended in $100 \mu \mathrm{l}$ Opti-MEM six times on day 5, 6, 7, 9, 11 and 13 post implantation. Mice that received DDP treatment were intraperitoneally injected DDP at $10 \mathrm{mg} / \mathrm{kg}$ on days 7,14 , and 21 . Control groups were scheduled to receive sham injections of Opti-MEM or PBS instead of injections of rMV-Hu191 or DDP. For animal survival, tumor volumes and weight were recorded every third day until day 11 post tumor implantation, and daily after day 11 , mice were euthanized when tumor volumes exceeded $1500 \mathrm{~mm}^{3}$ or body weight loss over $20 \%$.

\section{Evaluation of side-effects in vivo}

On day 13 post implantation, three mice from each group were sacrificed to harvest tumor tissues for analysis of apoptosis and angular vein blood for analysis of liver and kidney functions. Angular vein blood was collected to perform liver and kidney functions on an automated blood chemical pipeline analyzer (Beckman Coulter, USA).

\section{Immunohistochemistry (IHC)}

Tumor tissues were fixed in $4 \%$ formalin, embedded in paraffin, cut into $4 \mu \mathrm{m}$ slices, and stained with hematoxylin and eosin (H\&E) or indicated antibodies. Apoptotic cells in tumor sections were analyzed by an in situ Apoptosis Detection Kit (TUNEL, Takara, MK500). Color changes of the slides were photographed using light microscope with companion software (Leica, Germany).

\section{Statistical analysis}

All values were performed at least three independent experiments. Data were reported as mean \pm SE. Statistical significance between data sets was analyzed by Student's $t$ test and one-way ANOVA using GraphPad Prism 9.0. Survival analysis was calculated by the Kaplan-Meier method and compared by the log-rank test. $P$ value $<0.05$ was considered statistically significant. 
a

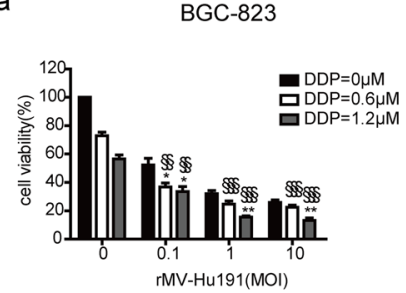

b

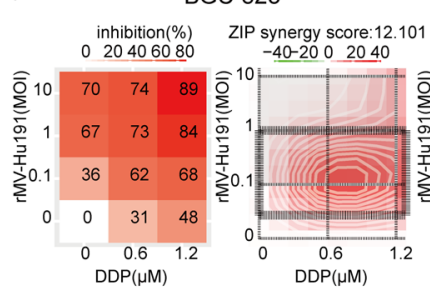

$\mathrm{DDP}(\mu \mathrm{M}) \& \mathrm{rMV}-\mathrm{Hu} 191(\mathrm{MOI})$

C

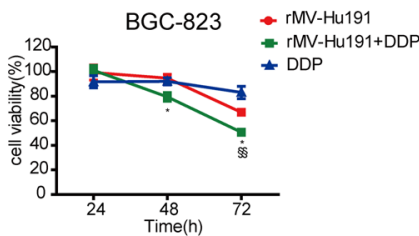

f
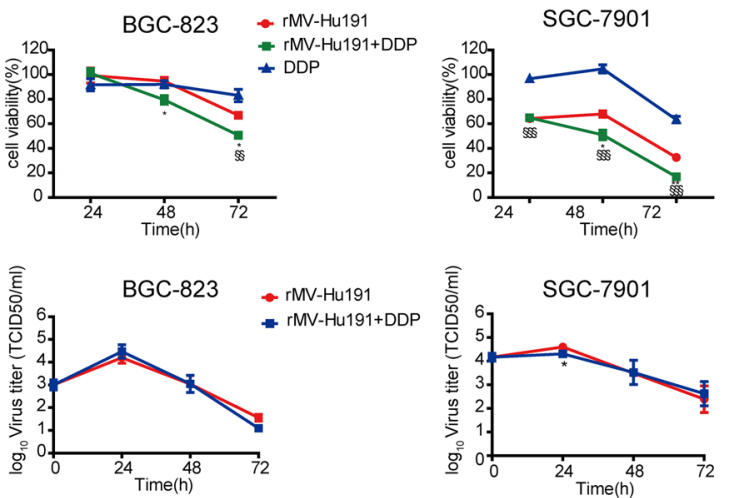

Fig. 1 rMV-Hu191 and DDP synergistically enhanced the cytotoxicity and caspase-dependent apoptosis in human GC cells. a Viability of BGC-823 and SGC-7901 cells after combinational treatment with rMV-Hu191 at different MOIs and DDP at indicated doses for $72 \mathrm{~h}$. Data presented as mean $\pm \mathrm{SE}$. b Inhibition and ZIP synergy score of rMV-Hu191 and DDP in BGC-823 and SGC-7901 cells. Circled area indicated the strongest synergistic region. $\mathbf{c}$ Viability of GC cells treated with rMV-Hu191 and DDP at different time points. MOI was 0.1 and 1 and the dose of DDP was 0.6 and $2.8 \mu \mathrm{M}$ in BGC-823 and SGC-7901 cells, respectively. * indicated comparison between the combinational and rMV-Hu191 treated groups, ${ }^{*} P<0.05, * * P<0.01$,

\section{Results}

\section{rMV-Hu191 synergistically enhanced the cytotoxicity of DDP in human GC cells}

As shown in Fig. 1a and Fig. s1, compared to treatment with rMV-Hu191 or DDP alone, their combination significantly augmented the cytotoxicity in GC cells. ZIP analysis confirmed that the interaction between rMV-Hu191 and DDP was almost universally synergistic over all the dose-response matrix in GC cells (Fig. 1b). For BGC-823 cells, the strongest synergistic effect was found within the region of dose combinations $(\mathrm{MOI}=0.1$ and $\mathrm{DDP}=0.6 \mu \mathrm{M})$ with average $\mathrm{ZIP}$ d

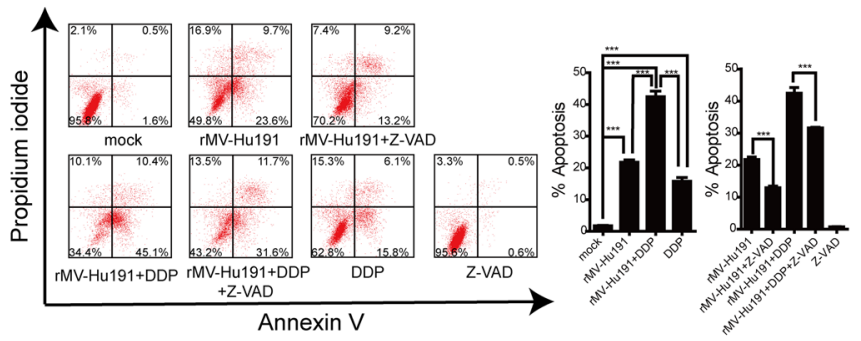

SGC-7901

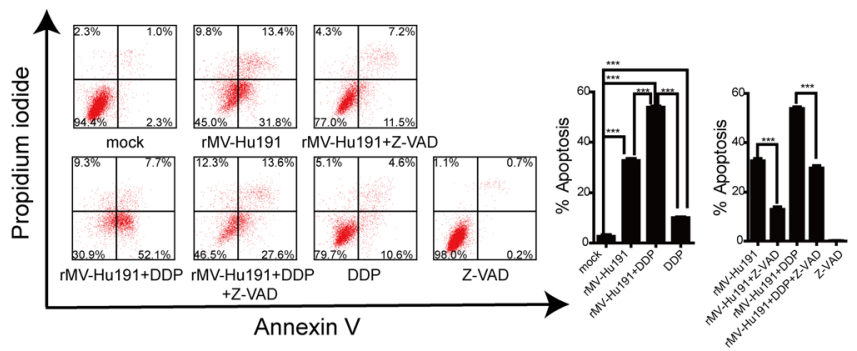

e

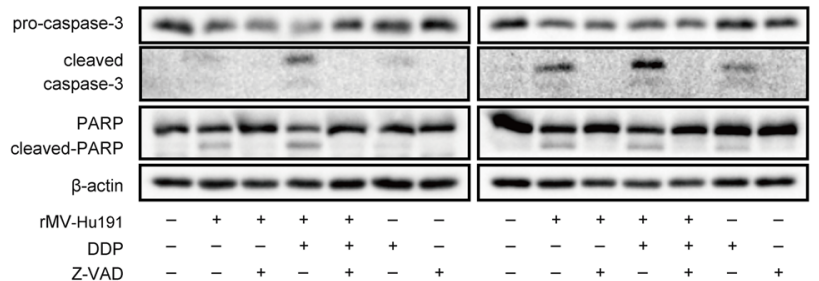

$* * * P<0.001$ (one-way ANOVA); $§$ indicated comparison between the combinational and DDP treated groups, ${ }^{\S} P<0.05,{ }^{\S} P<0.01$, ${ }^{\S \S} P<0.001$ (one-way ANOVA). d Ratio of apoptotic cells by flow cytometry analysis and expression of apoptosis marker proteins procaspase 3, cleaved-caspase-3, PARP, and cleaved-PARP in BGC-823 and SGC-7901 cells treated at the pre-determined condition that permitted synergism, in the presence or absence of Z-VAD $(100 \mu \mathrm{M})$ for 72 h. $* * * P<0.001$ (one-way ANOVA). f Virus particles were quantified by TCID 50 in GC cells treated with rMV-Hu191 alone or combination of rMV-Hu191 and DDP. ${ }^{*} P<0.05$ (student's $t$ test)

synergy scores 12.101. As for SGC-7901, the strongest synergistic effect was found within the region of dose combinations $(\mathrm{MOI}=1$ and $\mathrm{DDP}=2.8 \mu \mathrm{M})$ with average ZIP synergy scores 6.953. The time-dependent synergistic effect of rMV-Hu191 and DDP was initiatively detected at $48 \mathrm{~h}$ after combinational treatment with optimum doses according to the ZIP synergy scores (Fig. 1c). 


\section{rMV-Hu191 and DDP cooperated to trigger caspase-dependent apoptosis without virus progeny alteration in GC cells}

As shown in Fig. 1d, the current experiment exhibited that rMV-Hu191 in combination with DDP demonstrated a synergistic effect of caspase-dependent apoptosis which could be partially inhibited by Z-VAD (a pan-caspase inhibitor) in GC cells. The consistent results were confirmed by detecting the activation of apoptosis marker proteins caspase-3 and PARP (Fig. 1e). To explore whether the existence of DDP affected virus replication, we detected the virus growth curves. For both BGC-823 and SGC-7901 cells, there was almost no alternation in virus growth kinetics treated with rMV-Hu191 alone or combination with DDP (Fig. 1f, Fig. 2).

\section{Lipid rafts integrity was required for rMV-Hu191- and combination-induced apoptosis}

Lipid rafts integrity was disrupted by $\mathrm{M} \beta C D$ treatment dissolving cholesterol from cell membranes which was confirmed by the alteration of the position of flotillin 1 , a marker protein of lipid rafts (Fig. s3) [37]. As shown in
Fig. 2 rMV-Hu191- and combinational-treatment induced apoptosis required lipid rafts integrity. a Ratio of cell apoptosis after rMV-Hu191 and DDP treatment for $48 \mathrm{~h}$ in $\mathrm{BGC}-823$ $(\mathrm{MOI}=0.1, \mathrm{DDP}=0.6 \mu \mathrm{M})$ and SGC-7901 $(\mathrm{MOI}=0.1$, $\mathrm{DDP}=2.8 \mu \mathrm{M})$ cells, with or without M $\beta C D$ treatment. b Expression of apoptotic proteins after the same treatment as above. $* P<0.05$, $* * P<0.01$, $* * * P<0.001$

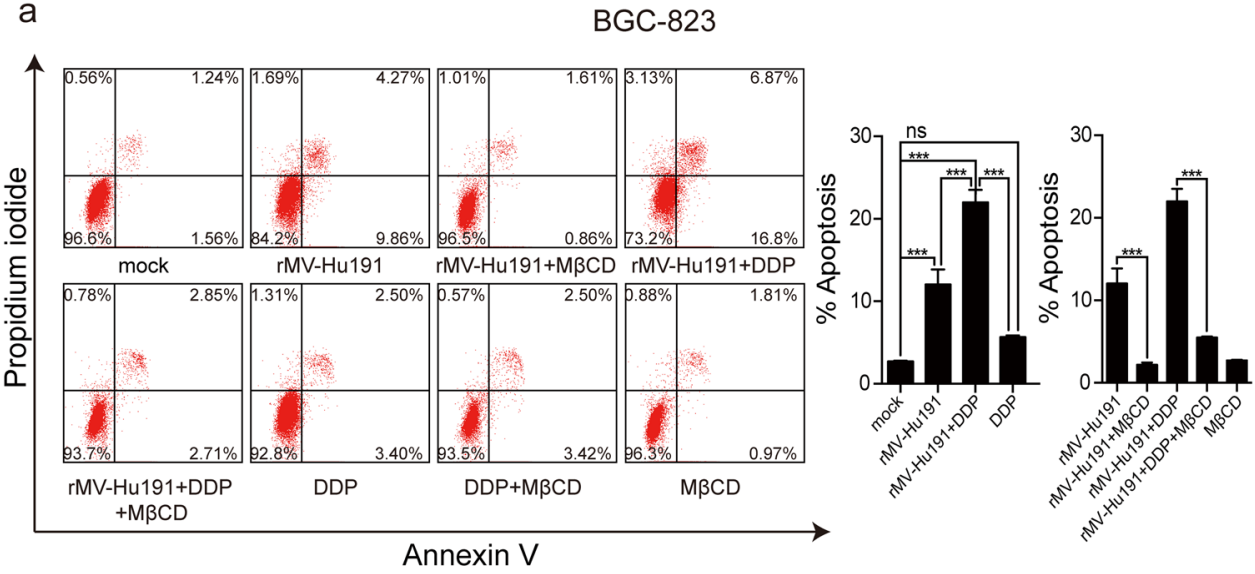

SGC-7901
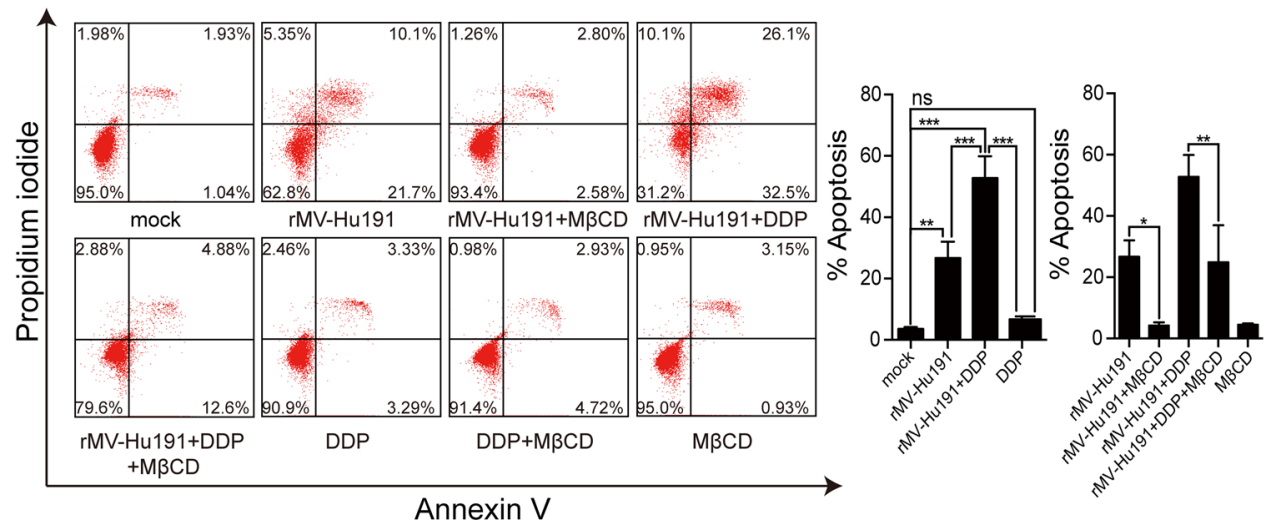

b

BGC-823

SGC-7901

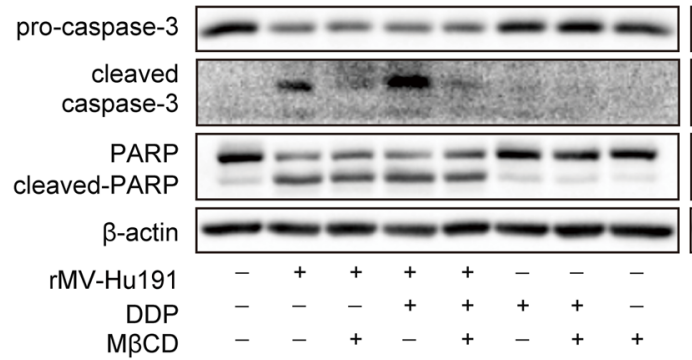


Fig. s4, the cells density of rMV-Hu191 and combination treatment was prominently reversed by $\mathrm{M} \beta \mathrm{CD}$. And the proportion of apoptosis in rMV-Hu191 group and combination group was significantly reversed after lipid rafts disruption using $M \beta C D$ (Fig. 2a). To further investigate lipid rafts requirement in the rMV-Hu191 and combination induced apoptosis, we detected the activation of caspase 3 and PARP. The cleavage of apoptosis proteins was remarkably decreased in the existence of $\mathrm{M} \beta \mathrm{CD}$ (Fig. 2b). These results suggested the vital role of lipid rafts in the synergistic effect of rMV-Hu191 and combination.

\section{ASMase participated in the rMV-Hu191 and combinational treatment induced apoptosis}

The representative microscopic images showed that cell density of rMV-Hu191 and combinational treatment was obviously increased in the presence of imipramine, an ASMase functional inhibitor (Fig. s5). And the ratio of apoptotic
Fig. 3 ASMase participated in rMV-Hu191- and combinationinduced apoptosis. a Ratio of cell apoptosis after rMVHu191 and DDP treatment for $48 \mathrm{~h}$ in $\mathrm{BGC}-823$ (MOI $=0.1$, $\mathrm{DDP}=0.6 \mu \mathrm{M})$ and SGC-7901 $(\mathrm{MOI}=0.1, \mathrm{DDP}=2.8 \mu \mathrm{M})$ cells, with or without imipramine treatment. b Expression of apoptotic proteins after the same treatment as above. c Protein levels of ASMase in wild-type SGC-7901 cells and SGC-7901 cells stably transfected with shASMase or shCtrl. $\mathbf{d}$ The expression of apoptotic proteins in wild-type SGC-7901 cells and SGC-7901 cells stably transfected with shASMase or shCtrl after rMVHu191 (MOI $=0.01)$ treatment for 72 h. $* P<0.05$, $* * P<0.01$, $* * * P<0.001$
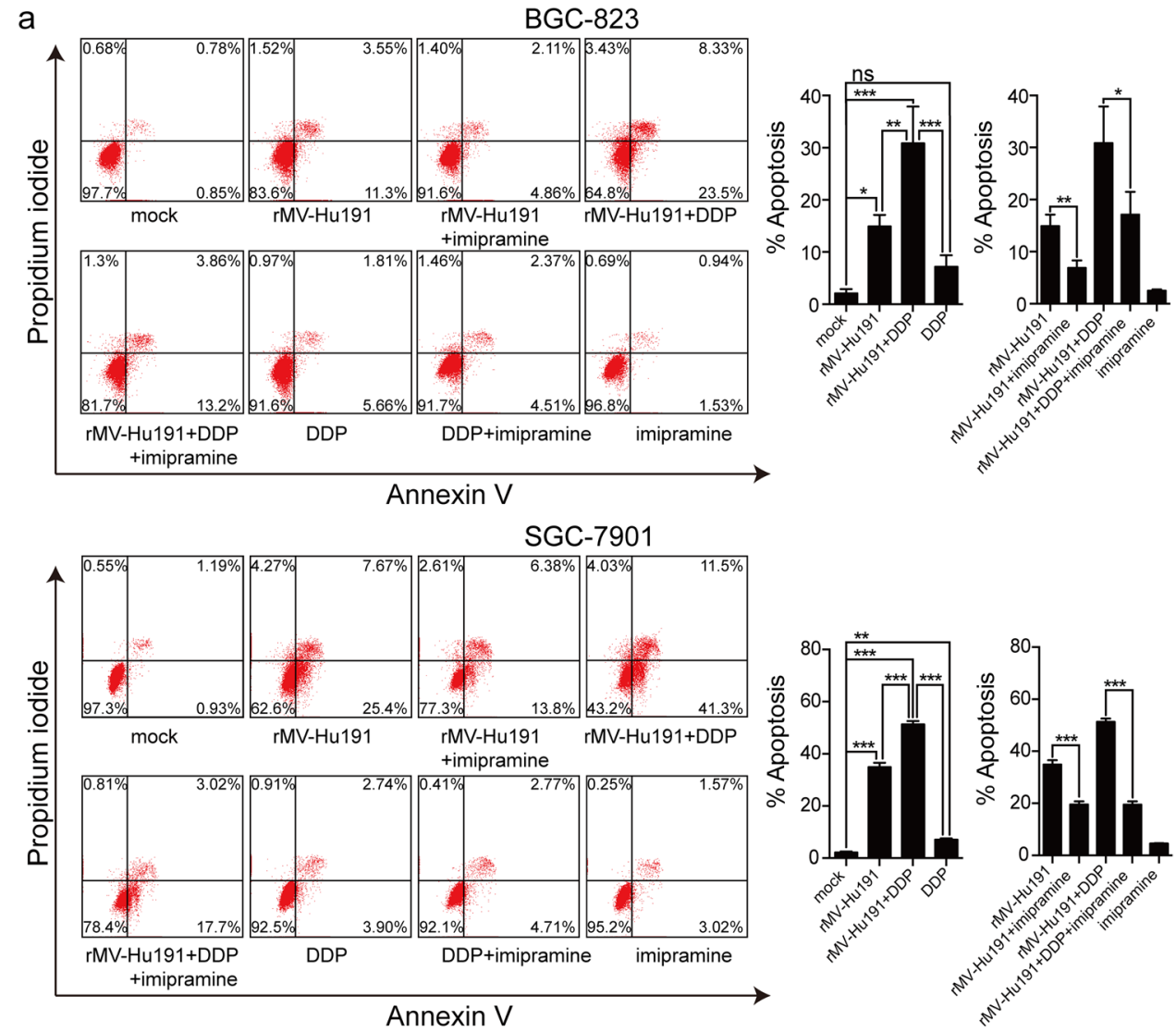

b

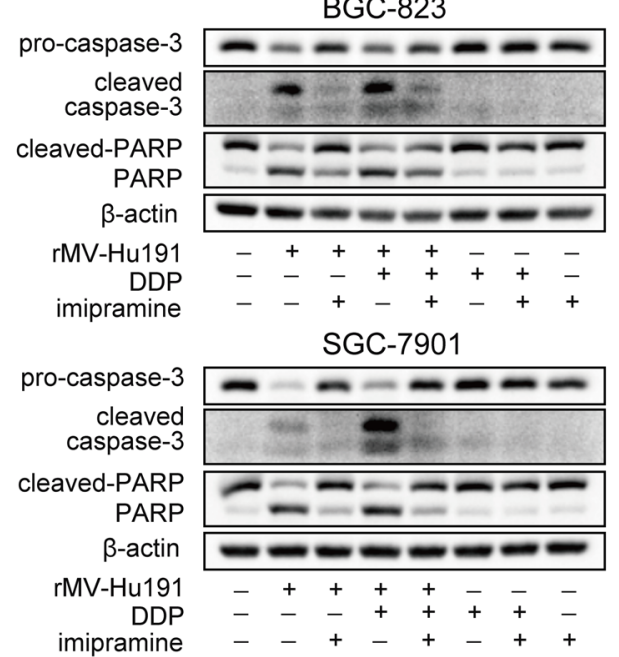

C

SGC-7901

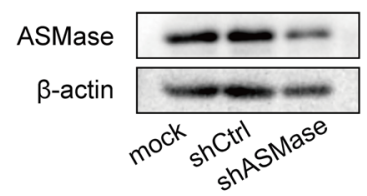

d

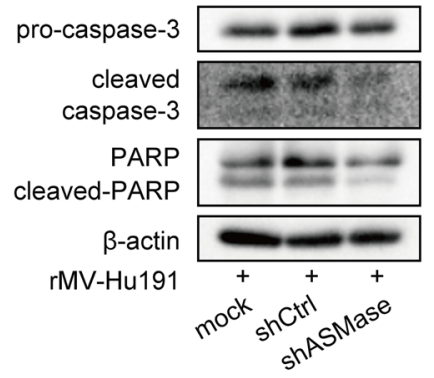


cells was prominently decreased after imipramine treatment (Fig. 3a). Imipramine treatment also markedly suppressed the cleavage of caspase- 3 and PARP (Fig. 3b). To further clarify the participation of ASMase in rMV-Hu191- and combination-induced apoptosis, we constructed SGC-7901 cells stably knockdown ASMase protein levels using shRNA (Fig. 3c). As shown in Fig. 3d and Fig. s6, ASMase depletion caused remarkable reduction in $\mathrm{rMV}-\mathrm{Hu} 191$-induced apoptosis and cytotoxicity in SGC-7901 cells. Taken together, these results confirmed the significance of ASMase in rMVHu191- and combination-induced apoptosis from the aspects of function and expression.

\section{rMV-Hu191 recruited ASMase to the lipid rafts}

According to the above results, we concluded that the antitumor effect was correlated with ASMase and lipid rafts, respectively. Therefore, we hypothesized that there existed
Fig. 4 Transfer of ASMase to lipid rafts in rMV-Hu191treated GC cells. a ASMase protein (red) was co-localized in CTB-labelled lipid rafts domains (green) after infection $(\mathrm{MOI}=5)$ for $8 \mathrm{~h}$ exhibited by immunofluorescence in GC cells. White arrows indicated co-localization areas of the two probes. Further confirm of the co-localization by $Z$-axis scanning from the three-dimensional level. Scale bar $=2 \mu \mathrm{m}$. b The expression of ASMase in GC cells treated with rMV-Hu191 $(\mathrm{MOI}=5)$ at the initial stage and the quantitative densitometry analysis from repeated blots. ASMase levels in BGC823 and SGC-7901cells $72 \mathrm{~h}$ after the indicated treatments, with or without $\mathrm{M} \beta \mathrm{CD}(\mathbf{c})$ and imipramine (d) coupled with the statistical significance based on triplicated WB data a

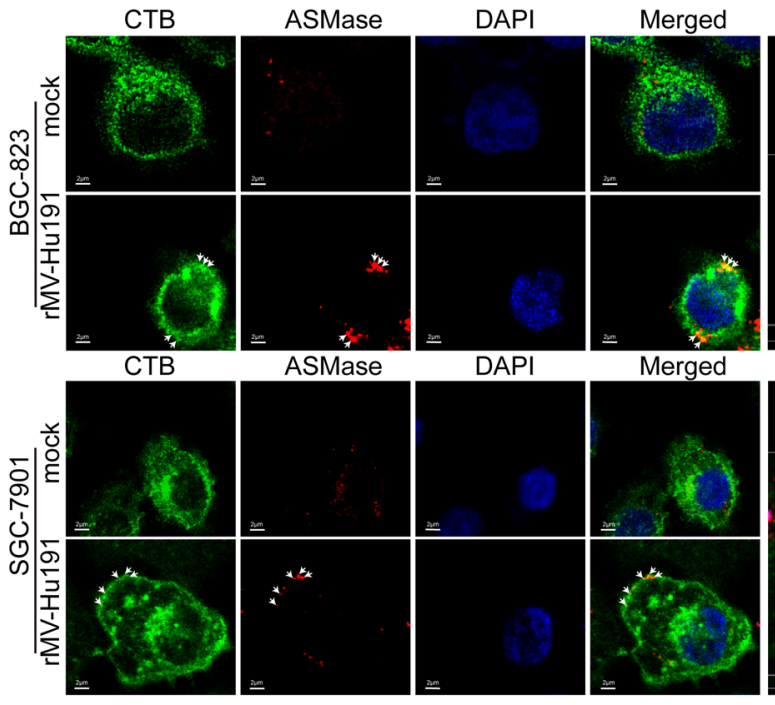

b

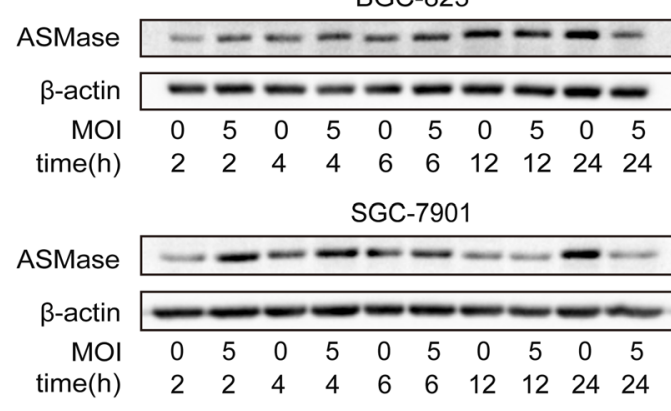

c

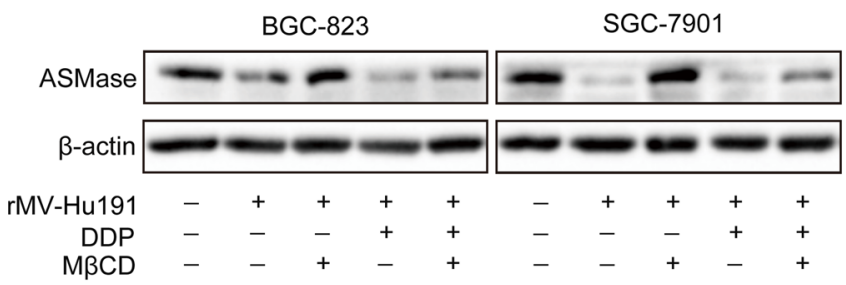

d

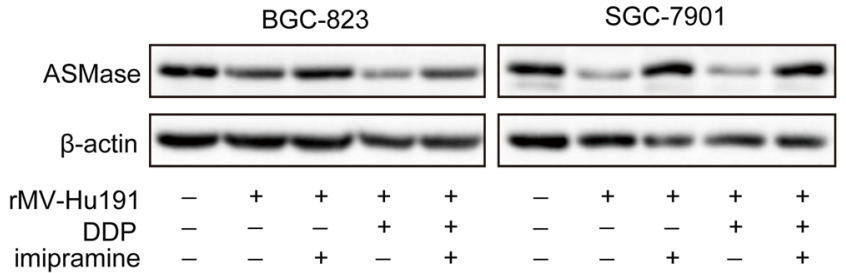

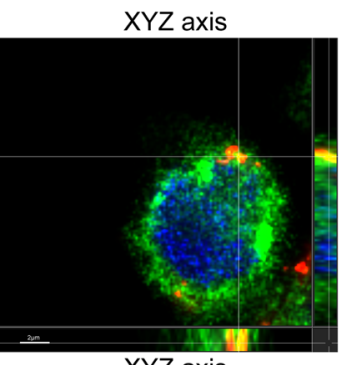
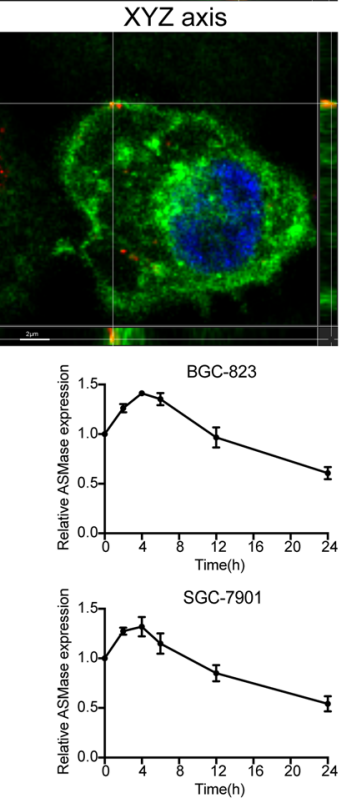

BGC-823
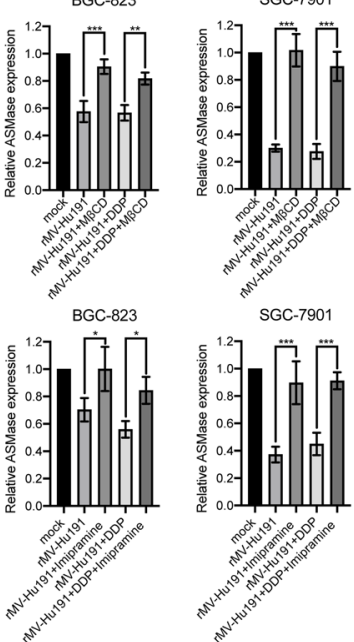
certain relationship between ASMase and lipid rafts in GC cells with rMV-Hu191 treatment. As shown in Fig. 4a and Fig. s7, ASMase was found to be concentrated and colocalized with lipid rafts domains on plasma membranes after rMV-Hu191 infection for $8 \mathrm{~h}$. The $Z$-axis scanning further confirmed the co-localization of ASMase and lipid rafts domains from the three-dimensional level. And the western blot results showed that after the rMV-Hu191 infection, the expression of ASMase increased at initial stage and then decreased (Fig. 4b and Fig. s8) with statistical differences. As shown in Fig. 4c, d and Fig. s9, the inhibition level of ASMase treated with rMV-Hu191 alone or combined treatment for $48 \mathrm{~h}$ was significantly reversed by culturing with $\mathrm{M} \beta C D$ and imipramine, respectively. In conclusion, the co-localization observed by immunofluorescence was consistent with the western blot results, and it revealed the translation of ASMase from cytoplasm to lipid rafts in GC cells infected with rMV-Hu191.

\section{Combined therapy synergized to suppress cell growth and increase apoptosis in a multi-drug-resistant signet ring cell GC cell line GCSR1}

To evaluate the clinical potential of the combined therapy, a multi-drug resistant GC cell line GCSR1, established from a Chinese male signet ring cell gastric cancer patient, which is resistant to cisplatin, 5-fluorouracil and mitomycin, was treated with rMV-Hu191 and DDP. Coincided with results of BGC-823 and SGC-7901 cells, combined therapy generated synergistic cytotoxicity in GCSR1 cells as well (Fig. 5a). The strongest synergistic effect was found within the region of dose combinations (MOI $=10$ and $\mathrm{DDP}=3 \mu \mathrm{M}$ ) with average ZIP synergy scores 19.387 (Fig. 5b). After treatment with optimum doses, the synergy was initially observed at $24 \mathrm{~h}$ with time-dependent manner (Fig. 5c). Furthermore, the combined treatment also dramatically augmented the caspase-dependent apoptotic cell death in GCSR1 (Fig. 5d).

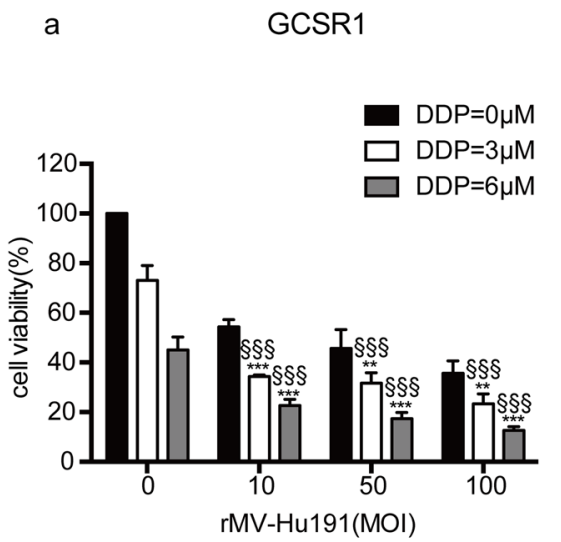

C

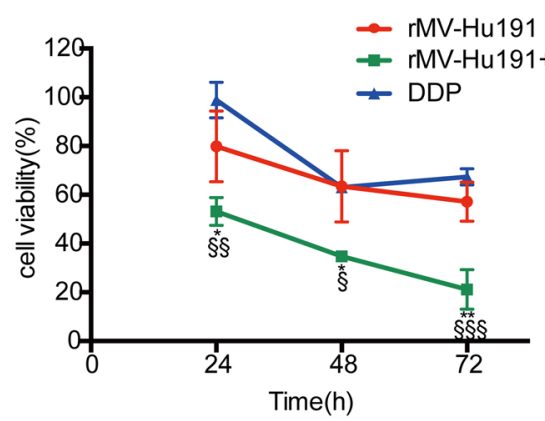

Fig. 5 rMV-Hu191 and DDP inhibited cell growth and increased apoptosis synergistically in a multi-drug-resistant signet ring cell GC cell line GCSR1. a Viability of GCSR1 cells after combinational treatment with rMV-Hu191 and DDP for $72 \mathrm{~h}$. Data presented as mean \pm SE. b Inhibition and ZIP synergy score of rMV-Hu191 and DDP in GCSR1 cells. Circled area indicated the strongest synergistic region. c Growth curves of GCSR1 cells treated with rMV- b

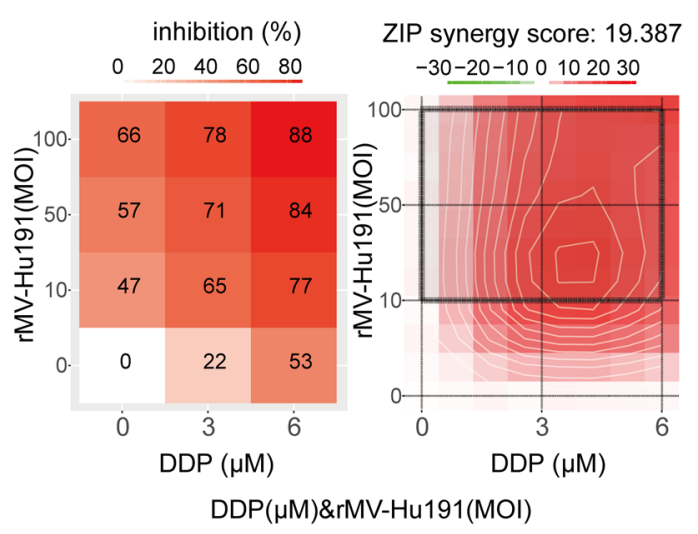

d

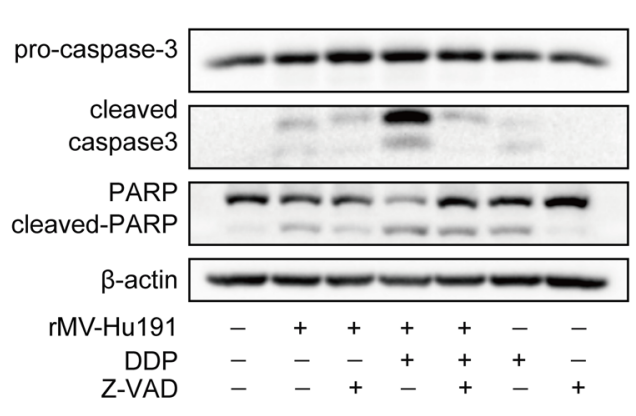

Hu191 (MOI = 10) and DDP $(6 \mu \mathrm{M})$. d Expression of apoptotic proteins in GCSR1 cells dealt with the synergistic treatment, in the presence or absence of Z-VAD $(100 \mu \mathrm{M})$ for $72 \mathrm{~h}$. * indicated comparison between the combinational- and rMV-Hu191-treated groups, $* P<0.05, * * P<0.01, * * * P<0.001$ (one-way ANOVA); ${ }^{\S}$ indicated comparison between the combinational- and DDP-treated groups, ${ }^{\S} P<0.05,{ }^{\S \S} P<0.01,{ }^{\S \S} P<0.001$ (one-way ANOVA) 


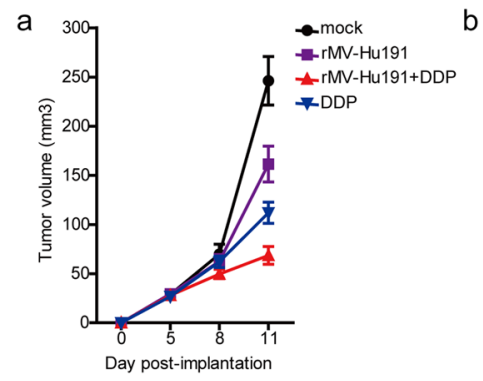

C
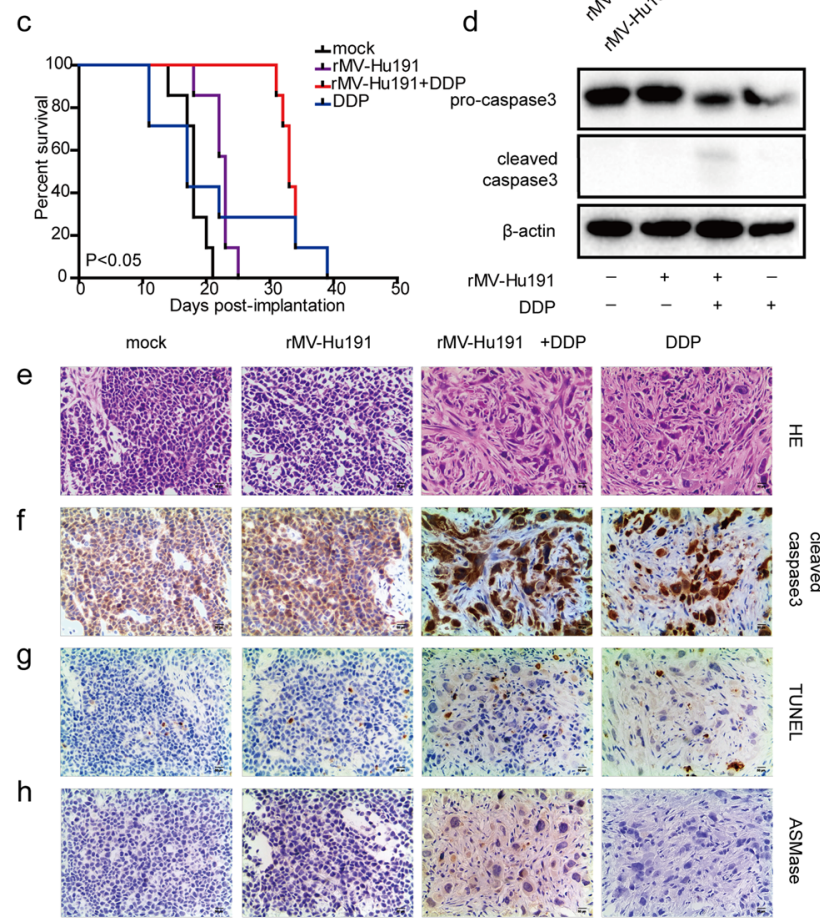

Fig. 6 Combinational treatment of rMV-Hu191 with DDP increased antitumor activity in vivo with trivial side-effects. a Tumor growth in mice bearing GC xenografts with desired treatments. b Difference in tumor volume on post-implantation day $11 .{ }^{*} P<0.05$, $* * P<0.01$, *** $P<0.001$ (unpaired $t$-test). c The survival rate of tumor-bearing mice. $P<0.05$ (log-rank test). d Expression of pro-caspase-3 and

\section{Combinational treatment increased antitumor activity in human GC xenografts with trivial side-effects}

Human GC xenografts were successfully established in nude mice to assess the in vivo effects of the combinational treatment. After 11-day treatment, the tumor regression effects were observed stronger in combined group than rMV-Hu191 group or DDP group (Fig. 6a, b). Administration of combinational treatment (median survival $=33$ days) resulted significantly prolonged survival compared with rMV-Hu191 (median survival $=23$ days) or DDP (median survival $=17$ days) treatment alone (Fig. 6c). H\&E staining from combined group showed distinct signs of tumor mass degradation, with large necrotic and apoptotic areas

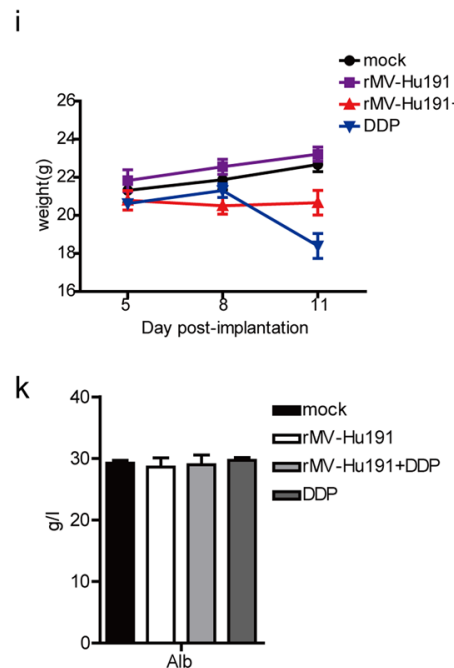

j
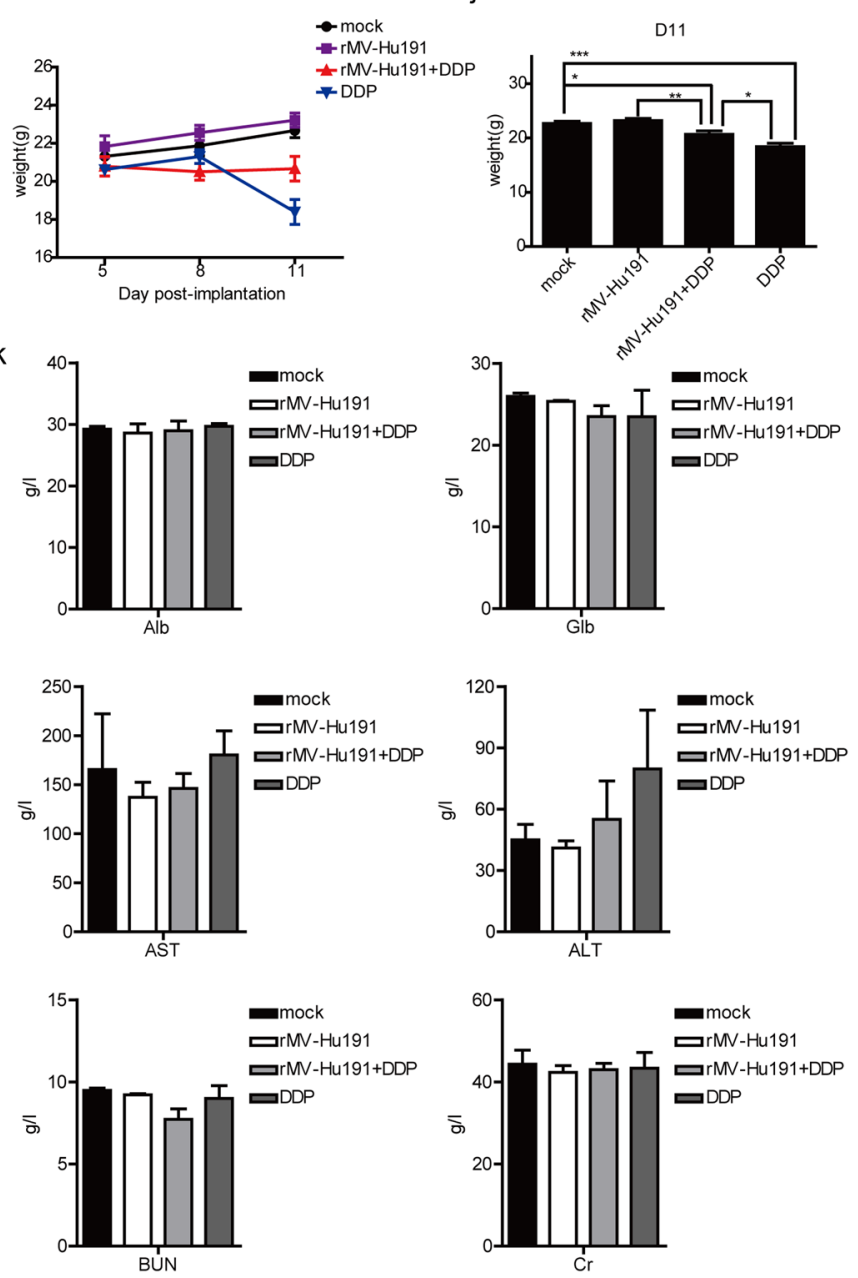

cleaved-caspase-3 in protein extracts from tumor tissues. HE staining (e), IHC of cleaved-caspase-3 (f) and ASMase (h), TUNEL (g) assays in tumor tissues. Scale bar $=50 \mu \mathrm{m}$. $\mathbf{i}, \mathbf{j}$ Body weight of mice bearing BGC-823 xenografts. $\mathbf{k}$ Evaluation of liver and kidney functions in mice. $* P<0.05, * * P<0.01, * * * P<0.001$ (one-way ANOVA)

containing tumor infiltrating cytoplasmic eosinophilia (Fig. 6e). Expression of apoptotic cells was considerably higher in co-treated tumors by detecting cleaved caspase 3 and in situ apoptosis using western blotting (Fig. 6d), IHC (Fig. 6f) and TUNEL analysis (Fig. 6g). And the expression level of ASMase was significantly increased by the rMVHu191 and combined treatment (Fig. 6h). Remarkably, the administration of DDP resulted in an obvious weight loss on day 11 , whereas the combinational treatment was well tolerant, suggesting that rMV-Hu191 could attenuate the side-effects of DDP (Fig. 6i, j). We further validated levels of Alb, Glb, AST, ALT, BUN, and $\mathrm{Cr}$ in angular vein blood to perform liver and kidney functions, and demonstrated that there was no statistical difference between treatment and control groups (Fig. 6k). Taken together, these results 
indicated that rMV-Hu191 could synergize the effects of DDP to inhibit tumor growth in vivo by augmenting apoptosis accompanying by trivial side-effects, which was in accordance with the mechanism in vitro.

\section{Discussion}

To increase the sensitization of chemotherapy, combination therapies of oncolytic MV Edmonston strain and chemotherapy and radiotherapy have been extensively explored [38-40]. Oncolytic MV in combination with chemotherapeutics is more promising, since both primary tumors and metastases can be efficiently treated by such regimens. With the same advantage as a MV strain, the safety of Chinese Hu-191 strain derivatives has been proved in the application of vaccination in China [41]. Our study is the first to prove that combination therapy of oncolytic MV Chinese Hu-191strain and DDP could serve as a promising strategy in GC treatment. From our data, rMV-Hu191 in combination with DDP synergistically induced stronger antitumor effect than rMV-Hu191 or DDP alone in two human GC cell lines and one multi-drug-resistant GC cell line. Importantly, ZIP analysis revealed synergistic activity of this chemovirotherapy strategy, with higher average synergy scores in GSCR1 cells than that of SGC-7901 and BGC-823 cells. In literature reports, whether chemical drug would hamper virus replication lacked consistency [42, 43]. However, in our study, there was almost no alternation of virus growth kinetics in GC cells treated with rMV-Hu191 alone or combination with DDP. In vivo studies confirmed that intratumoral rMV-Hu191 injection combined with intraperitoneal DDP injection resulted in a significant reduction in tumor growth compared with rMV-Hu191 alone or DDP alone injection, and prolonged the survival of human GC xenografts significantly. And the body weight of the combination group was slightly heavier than that of the DDP group, indicating that the toxicity of DDP could be partially reduced by combination of rMV-Hu191.

Apoptosis, known as programed cell death, is controlled by genes and a series of enzymes [44], and has been recognized as the common fate of cancer cells during therapy [45]. DDP can induce apoptosis in GC cells [46]. In this study, we found that rMV-Hu191 combined with DDP exhibited significant antitumor effect against GC through induction of caspase-dependent apoptosis both in vitro and vivo. In both two GC cell lines and one multi-drug-resistant GC cell line, the ratio of apoptotic cells and the expression of activated caspase 3 and PARP were significantly increased in combined group compared to rMV-Hu191 or DDP alone group. Furthermore, the pan-caspase inhibitor Z-VAD could partially reverse the induction of apoptotic cell death after rMVHu191 or combinational treatment. In BGC-823 xenografts, induction of caspase-dependent apoptosis was approved by in situ detection of caspase 3 activation and TUNEL assay. Therefore, the capability to induce caspase-dependent apoptosis was the major mechanism for rMV-Hu191 combined DDP to synergistically inhibit GC.

Lipid rafts were specific regions of membranes which were rich in sphingolipids and cholesterols [47], and were involved in many cellular processes including signal transduction, membrane trafficking, skeletal reconstruction [48]. Lipid rafts disruption following treatment with the $\mathrm{M} \beta \mathrm{CD}$, a most common cholesterol-depleting agent, inhibited both rMV-Hu191-induced and rMV-Hu191 plus DDP-induced apoptosis in the two GC cell lines (Fig. 2). These results indicated that lipid rafts could influence rMV-Hu191- and combination-induced apoptosis.

It is well known that ASMase can hydrolyze SM to generate ceramide [49]. Ceramide, a bioactive sphingolipid, was a key regulator in the initiation step of apoptosis [50].

When plasma membrane was wounded by exposure to the bacterial or virus, the lysosomal ASMase can be delivered to the outer leaflet of the plasma membrane, the later event would stimulate ceramide generation and apoptosis initiation [51]. From our data, the expression of ASMase increased at initial stage in vitro and in vivo and then decreased in vitro (Figs. 4b, 6h). Inhibition of ASMase activation by imipramine, an inhibitor of acid sphingomyelinase, could reduce the ratio of apoptotic cells and the expression of activated caspase 3 and PARP in rMV-Hu191 and rMV-Hu191 plus DDP treated GC (Fig. 3). Moreover, reduction the level of ASM by shRNA, could also reverse the rMV-Hu191induced and rMV-Hu191 plus DDP-induced of apoptotic cell death (Fig. 3). To verify an interaction between ASMase and lipid rafts, immunofluorescence analyses were performed. According to the obtained results, co-localization of ASMase with the lipid rafts marker CTB was visible after early infection of rMV-Hu191 (Fig. 4a) and the expression level of ASMase within GC cell could be reversed by $\mathrm{M} \beta \mathrm{CD}$ and imipramine (Fig. 4c, d). Our data suggested that ASMase transferred from cytosol to plasma membrane lipid raft microdomains in the early stage and played a central role in rMV-Hu191- and combination-induced GC apoptosis.

Based on the above data, our findings are consistent with the following mechanism (Fig. 7): First of all, the ASMase within cytoplasmic was activated and translocated to plasma membrane lipid raft microdomains during early stages of rMV-Hu191 infection. The later phase is based on the integrity of lipid raft microdomains and the ceramide induction might be involved it. Lastly, rMV-Hu191 and DDP cooperated to trigger caspase-dependent apoptosis in GC cells.

In conclusion, our findings suggested that combination of rMV-Hu191 with DDP chemotherapy has potent and synergistic therapeutic efficacy against human GC both in vivo and in vitro by ASMase-mediated apoptosis requiring 
Fig. 7 Schematic illustration of the combination of rMVHu191- and DDP-induced antitumor effects

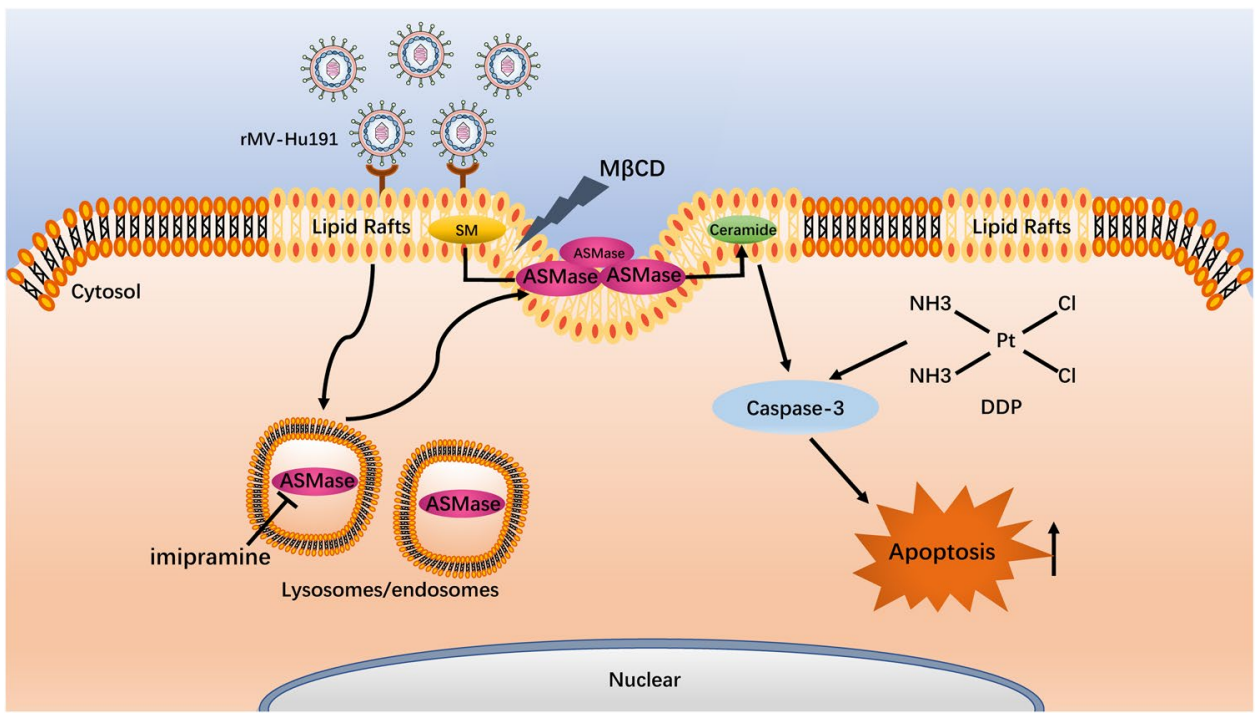

integrity of lipid raft microdomains. Due to the relatively low side effects of rMV-Hu191, co-administration of rMVHu191 could serve as a safe and effective strategy. Taken together, the combinational chemovirotherapy investigated here could potentially serve as an adjuvant therapy against human GC.

Supplementary Information The online version contains supplementary material available at https://doi.org/10.1007/s10120-021-01210-8.

Acknowledgements This work was funded by the Zhejiang Provincial Science technology research program (2017C33047). And we appreciated the professor Li-song Teng from the 1st Affiliated Hospital Zhejiang University School of Medicine for providing the multi-drugresistant signet ring cell GCSR1.

Author contribution Conceived and designed the experiments: Zhengyan Zhao, Yao Lv, Chu-di Zhang. Performed the experiments: Yao Lv, Chu-di Zhang, Yi-long Wang, Dong-ming Zhou, Meng-ying Zhu, Xiao-qiang Hao, Jin-hu Wang, Wei-zhong Gu, Hong-qiang Shen, Jingan Lou, Ben-qing Wu, Pei-chun Chen. Wrote the manuscript: Yao Lv, Chu-di Zhang. All authors read and approved the final manuscript.

\section{Declarations}

Conflict of interest The authors declare that they have no conflict of interest.

Open Access This article is licensed under a Creative Commons Attribution 4.0 International License, which permits use, sharing, adaptation, distribution and reproduction in any medium or format, as long as you give appropriate credit to the original author(s) and the source, provide a link to the Creative Commons licence, and indicate if changes were made. The images or other third party material in this article are included in the article's Creative Commons licence, unless indicated otherwise in a credit line to the material. If material is not included in the article's Creative Commons licence and your intended use is not permitted by statutory regulation or exceeds the permitted use, you will need to obtain permission directly from the copyright holder. To view a copy of this licence, visit http://creativecommons.org/licenses/by/4.0/.

\section{References}

1. Goetze OT, Al-Batran SE, Chevallay M, Monig SP. Multimodal treatment in locally advanced gastric cancer. Updates Surg. 2018;70:173-9.

2. Smyth EC, Nilsson M, Grabsch HI, van Grieken NCT, Lordick F. Gastric cancer. The Lancet. 2020;396:635-48.

3. Song Z, Wu Y, Yang J, Yang D, Fang X. Progress in the treatment of advanced gastric cancer. Tumour Biol. 2017;39:1010428317714626.

4. Kobayashi D, Kodera Y. Intraperitoneal chemotherapy for gastric cancer with peritoneal metastasis. Gastric Cancer. 2017;20:111-21.

5. Eljack ND, Ma HY, Drucker J, Shen C, Hambley TW, New EJ, Friedrich T, Clarke RJ. Mechanisms of cell uptake and toxicity of the anticancer drug cisplatin. Metallomics. 2014;6:2126-33.

6. Zhou D, Liu W, Liang S, Sun B, Liu A, Cui Z, Han X, Yuan L. Apoptin-derived peptide reverses cisplatin resistance in gastric cancer through the PI3K-AKT signaling pathway. Cancer Med. 2018;7:1369-83.

7. Hemminki O, Oksanen M, Taipale K, Liikanen I, Koski A, Joensuu T, Kanerva A, Hemminki A. Oncograms visualize factors influencing long-term survival of cancer patients treated with adenoviral oncolytic immunotherapy. Mol Ther Oncolyt. 2018;9:41-50.

8. Comins C, Spicer J, Protheroe A, Roulstone V, Twigger K, White CM, Vile R, Melcher A, Coffey MC, Mettinger KL, Nuovo G, Cohn DE, Phelps M, Harrington KJ, Pandha HS. REO-10: A phase i study of intravenous reovirus and docetaxel in patients with advanced cancer. Clin Cancer Res. 2010;16:5564-72.

9. Karapanagiotou EM, Roulstone V, Twigger K, Ball M, Tanay M, Nutting C, Newbold K, Gore ME, Larkin J, Syrigos KN, Coffey M, Thompson B, Mettinger K, Vile RG, Pandha HS, Hall GD, Melcher AA, Chester J, Harrington KJ. Phase I/II trial of carboplatin and paclitaxel chemotherapy in combination with intravenous oncolytic reovirus in patients with advanced malignancies. Clin Cancer Res. 2012;18:2080-9.

10. Mell LK, Brumund KT, Daniels GA, Advani SJ, Zakeri K, Wright ME, Onyeama SJ, Weisman RA, Sanghvi PR, Martin PJ, Szalay AA. Phase I trial of intravenous oncolytic vaccinia virus (GLONC1) with cisplatin and radiotherapy in patients with locoregionally advanced head and neck carcinoma. Clin Cancer Res. 2017;23:5696-702. 
11. Chen A, Zhang Y, Meng G, Jiang D, Zhang H, Zheng M, Xia M, Jiang A, Wu J, Beltinger C, Wei J. Oncolytic measles virus enhances antitumour responses of adoptive CD8(+)NKG2D(+) cells in hepatocellular carcinoma treatment. Sci Rep. 2017;7:5170.

12. Jing Y, Chavez V, Ban Y, Acquavella N, El-Ashry D, Pronin A, Chen X, Merchan JR. Molecular effects of stromal-selective targeting by uPAR-retargeted oncolytic virus in breast cancer. Mol Cancer Res. 2017;15:1410-20.

13. Rahal A, Musher B. Oncolytic viral therapy for pancreatic cancer. J Surg Oncol. 2017;116:94-103.

14. Jing Y, Zaias J, Duncan R, Russell SJ, Merchan JR. In vivo safety, biodistribution and antitumor effects of UPAR retargeted oncolytic measles virus in syngeneic cancer models. Gene Ther. 2014;21:289-97.

15. Heinzerling L, Kunzi V, Oberholzer PA, Kundig T, Naim H, Dummer R. Oncolytic measles virus in cutaneous T-cell lymphomas mounts antitumor immune responses in vivo and targets interferon-resistant tumor cells. Blood. 2005;106:2287-94.

16. Galanis E, Hartmann LC, Cliby WA, Long HJ, Peethambaram PP, Barrette BA, Kaur JS, Haluska PJ Jr, Aderca I, Zollman PJ, Sloan JA, Keeney G, Atherton PJ, Podratz KC, Dowdy SC, Stanhope CR, Wilson TO, Federspiel MJ, Peng KW, Russell SJ. Phase I trial of intraperitoneal administration of an oncolytic measles virus strain engineered to express carcinoembryonic antigen for recurrent ovarian cancer. Cancer Res. 2010;70:875-82.

17. Lech PJ, Russell SJ. Use of attenuated paramyxoviruses for cancer therapy. Expert Rev Vaccines. 2010;9:1275-302.

18. Weiland T, Lampe J, Essmann F, Venturelli S, Berger A, Bossow S, Berchtold S, Schulze-Osthoff K, Lauer UM, Bitzer M. Enhanced killing of therapy-induced senescent tumor cells by oncolytic measles vaccine viruses. Int J Cancer. 2014;134:235-43.

19. Griffin DE. Measles vaccine. Viral Immunol. 2018;31:86-95.

20. Zhang Y, Zhou J, Bellini WJ, Xu W, Rota PA. Genetic characterization of Chinese measles vaccines by analysis of complete genomic sequences. J Med Virol. 2009;81:1477-83.

21. Wang Y, Liu R, Lu M, Yang Y, Zhou D, Hao X, Zhou D, Wang B, Li J, Huang YW, Zhao Z. Enhancement of safety and immunogenicity of the Chinese Hu191 measles virus vaccine by alteration of the S-adenosylmethionine (SAM) binding site in the large polymerase protein. Virology. 2018;518:210-20.

22. Lv Y, Zhou D, Hao XQ, Zhu MY, Zhang CD, Zhou DM, Wang JH, Liu RX, Wang YL, Gu WZ, Shen HQ, Chen X, Zhao ZY. A recombinant measles virus vaccine strain rMV-Hu191 has oncolytic effect against human gastric cancer by inducing apoptotic cell death requiring integrity of lipid raft microdomains. Cancer Lett. 2019;460:108-18.

23. Zhang CD, Wang YL, Zhou DM, Zhu MY, Lv Y, Hao XQ, Qu $\mathrm{CF}$, Chen Y, Gu WZ, Wu BQ, Chen PC, Zhao ZY. A recombinant Chinese measles virus vaccine strain rMV-Hu191 inhibits human colorectal cancer growth through inducing autophagy and apoptosis regulating by PI3K/AKT pathway. Transl Oncol. 2021;14:101091

24. Xu X, Lai Y, Hua ZC. Apoptosis and apoptotic body: disease message and therapeutic target potentials. Biosci Rep 2019;39.

25. Mullen TD, Obeid LM. Ceramide and apoptosis: exploring the enigmatic connections between sphingolipid metabolism and programmed cell death. Anticancer Agents Med Chem. 2012;12:340-63.

26. Alves ACS, Dias RA, Kagami LP, das Neves GM, Torres FC, Eifler-Lima VL, Carvalho I, de Miranda Silva C, Kawano DF. Beyond the "lock and key" paradigm: targeting lipid rafts to induce the selective apoptosis of cancer cells. Curr Med Chem. 2018;25:2082-104.

27. Xiong ZJ, Huang J, Poda G, Pomes R, Prive GG. Structure of human acid sphingomyelinase reveals the role of the saposin domain in activating substrate hydrolysis. J Mol Biol. 2016;428:3026-42.

28. Segui B, Legembre P. Redistribution of CD95 into the lipid rafts to treat cancer cells? Recent Pat Anticancer Drug Discov. 2010;5:22-8.

29. Cepeda V, Fuertes MA, Castilla J, Alonso C, Quevedo C, Pérez JM. Biochemical mechanisms of cisplatin cytotoxicity. Anticancer Agents Med Chem. 2007;7:3-18.

30. Fuertes MA, Castilla J, Alonso C, Pérez JM. Cisplatin biochemical mechanism of action: from cytotoxicity to induction of cell death through interconnections between apoptotic and necrotic pathways. Curr Med Chem. 2003;10:257-66.

31. Wang W, Zhou Y, Yao Q, Liu W, Xiang L, Ni T, Dai X, Liu Y. Celastrus orbiculatus extract potentiates the sensitivity of cisplatin via caspase-dependent apoptosis in gastric cancer. Anticancer Agents Med Chem. 2018;18:2206-11.

32. You HY, Xie XM, Zhang WJ, Zhu HL, Jiang FZ. Berberine modulates cisplatin sensitivity of human gastric cancer cells by upregulation of miR-203. Vitro Cell Dev Biol Anim. 2016;52:857-63.

33. Xu X, Qian LJ, Su XY, He KF, Jin KT, Gu LH, Feng JG, Li GL, Zhou Q, Xu ZZ, Wang HH, Zhang J, Cao J, Teng LS. Establishment and characterization of GCSR1, a multi-drug resistant signet ring cell gastric cancer cell line. Int J Oncol. 2015;46:2479-87.

34. Yadav B, Wennerberg K, Aittokallio T, Tang J. Searching for drug synergy in complex dose-response landscapes using an interaction potency model. Comput Struct Biotechnol J. 2015;13:504-13.

35. Torres NS, Montelongo-Jauregui D, Abercrombie JJ, Srinivasan A, Lopez-Ribot JL, Ramasubramanian AK, Leung KP. Antimicrobial and antibiofilm activity of synergistic combinations of a commercially available small compound library with colistin against Pseudomonas aeruginosa. Front Microbiol. 2018;9:2541.

36. Ramakrishnan MA. Determination of $50 \%$ endpoint titer using a simple formula. World J Virol. 2016;5:85-6.

37. Yokoyama H, Matsui I. The lipid raft markers stomatin, prohibitin, flotillin, and HflK/C (SPFH)-domain proteins form an operon with $\mathrm{NfeD}$ proteins and function with apolar polyisoprenoid lipids. Crit Rev Microbiol. 2020;46:38-48.

38. Kaufmann JK, Bossow S, Grossardt C, Sawall S, Kupsch J, Erbs P, Hassel JC, von Kalle C, Enk AH, Nettelbeck DM, Ungerechts G. Chemovirotherapy of malignant melanoma with a targeted and armed oncolytic measles virus. J Investig Dermatol. 2013;133:1034-42.

39. Zaoui K, Bossow S, Grossardt C, Leber MF, Springfeld C, Plinkert PK, Kalle C, Ungerechts G. Chemovirotherapy for head and neck squamous cell carcinoma with EGFR-targeted and CD/UPRT-armed oncolytic measles virus. Cancer Gene Ther. 2012;19:181-91.

40. Touchefeu Y, Khan AA, Borst G, Zaidi SH, McLaughlin M, Roulstone V, Mansfield D, Kyula J, Pencavel T, Karapanagiotou EM, Clayton J, Federspiel MJ, Russell SJ, Garrett M, Collins I, Harrington KJ. Optimising measles virus-guided radiovirotherapy with external beam radiotherapy and specific checkpoint kinase 1 inhibition. Radiother Oncol. 2013;108:24-31.

41. Ma C, Hao L, Zhang Y, Su Q, Rodewald L, An Z, Yu W, Ma J, Wen N, Wang H, Liang X, Wang H, Yang W, Li L, Luo H. Monitoring progress towards the elimination of measles in China: an analysis of measles surveillance data. Bull World Health Organ. 2014;92:340-7.

42. Myers RM, Greiner SM, Harvey ME, Griesmann G, Kuffel MJ, Buhrow SA, Reid JM, Federspiel M, Ames MM, Dingli D, Schweikart K, Welch A, Dispenzieri A, Peng KW, Russell SJ. Preclinical pharmacology and toxicology of intravenous MV-NIS, an oncolytic measles virus administered with or without cyclophosphamide. Clin Pharmacol Ther. 2007;82:700-10. 
43. Yurttas C, Berchtold S, Malek NP, Bitzer M, Lauer UM. Pulsed versus continuous application of the prodrug 5-fluorocytosine to enhance the oncolytic effectiveness of a measles vaccine virus armed with a suicide gene. Hum Gene Ther Clin Dev. 2014;25:85-96.

44. Galluzzi L, Vitale I, Aaronson SA. Molecular mechanisms of cell death: recommendations of the Nomenclature Committee on Cell Death 2018. Cell Death Differ. 2018;25:486-541.

45. Hassan M, Watari H, AbuAlmaaty A, Ohba Y, Sakuragi N. Apoptosis and molecular targeting therapy in cancer. Biomed Res Int. 2014;2014:150845.

46. Yan R, Li K, Yuan DW, Wang HN, Zhang Y, Dang CX, Zhu K. Downregulation of microRNA-4295 enhances cisplatin-induced gastric cancer cell apoptosis through the EGFR/PI3K/Akt signaling pathway by targeting LRIG1. Int J Oncol. 2018;53:2566-78.

47. Calder PC, Yaqoob P. Lipid rafts-composition, characterization, and controversies. J Nutr. 2007;137:545-7.

48. Munro S. Lipid rafts: elusive or illusive? Cell. 2003;115:377-88.
49. Tam C, Idone V, Devlin C, Fernandes MC, Flannery A, He X, Schuchman E, Tabas I, Andrews NW. Exocytosis of acid sphingomyelinase by wounded cells promotes endocytosis and plasma membrane repair. J Cell Biol. 2010;189:1027-38.

50. Chang KT, Anishkin A, Patwardhan GA, Beverly LJ, Siskind LJ, Colombini M. Ceramide channels: destabilization by Bcl-xL and role in apoptosis. Biochim Biophys Acta. 1848;2015:2374-84.

51. Gilbert S, Loranger A, Omary MB, Marceau N. Keratin impact on PKCdelta- and ASMase-mediated regulation of hepatocyte lipid raft size-implication for FasR-associated apoptosis. J Cell Sci. 2016;129:3262-73.

Publisher's Note Springer Nature remains neutral with regard to jurisdictional claims in published maps and institutional affiliations.

\section{Authors and Affiliations}

\section{Yao Lv ${ }^{1} \cdot$ Chu-di Zhang ${ }^{2} \cdot$ Yi-long Wang ${ }^{2} \cdot$ Dong-ming Zhou ${ }^{2} \cdot$ Meng-ying Zhu $^{2} \cdot$ Xiao-qiang Hao $^{2}$. Jin-hu Wang ${ }^{2}$. Wei-zhong Gu${ }^{2} \cdot$ Hong-qiang Shen ${ }^{2} \cdot$ Jin-gan Lou $^{2} \cdot$ Ben-qing Wu ${ }^{3} \cdot$ Pei-chun Chen ${ }^{3} \cdot$ Zheng-yan Zhao $^{2}$}

Yao Lv

21418068@zju.edu.cn

Chu-di Zhang

21718442@zju.edu.cn

Yi-long Wang

11418155@zju.edu.cn

Dong-ming Zhou

21318243@zju.edu.cn

Meng-ying Zhu

11618182@zju.edu.cn

Xiao-qiang Hao

11718196@zju.edu.cn

Jin-hu Wang

wjh@zju.edu.cn

Wei-zhong Gu

6195013@zju.edu.cn
Hong-qiang Shen

shenhq@zju.edu.cn

Jin-gan Lou

jinganlou@zju.edu.cn

Ben-qing Wu

wubenqing783@126.com

Pei-chun Chen

674870541@qq.com

1 Gastroenterology Department, Children's Hospital, Zhejiang University School of Medicine, Hangzhou 310051, Zhejiang, China

2 Children's Hospital, Zhejiang University School of Medicine, Hangzhou 31005, Zhejiang, China

3 University of Chinese Academy of Sciences, Shenzhen Hospital, Shenzhen 518000, China 